\title{
Transcriptional Profile Corroborates that $b m l$ Mutant Plays likely Role in Premature Leaf Senescence of Rice (Oryza sativa L.)
}

\author{
Delara Akhter ${ }^{1,2}$, Ran Qin ${ }^{1}$, Ujjal Kumar Nath ${ }^{3}$, Jamal Eshag ${ }^{1}$, Xiaoli Jin ${ }^{1}$ and Chunhai Shi ${ }^{1, *}$ \\ 1 Department of Agronomy, Zhejiang University, Hangzhou 310027, China; 11516090@zju.edu.cn (D.A.); \\ ranqin89@zju.edu.cn (R.Q.); jamaladam@zju.edu.cn (J.E.); jinxl@zju.edu.cn (X.J.) \\ 2 Department of Genetics and Plant Breeding, Sylhet Agricultural University, Sylhet 3100, Bangladesh \\ 3 Department of Genetics and Plant Breeding, Bangladesh Agricultural University, Mymensingh 2202, \\ Bangladesh; ujjalnath@gmail.com \\ * Correspondence: chhshi@zju.edu.cn; Tel./Fax: +86-571-8898-2691
}

Received: 24 March 2019; Accepted: 3 April 2019; Published: 5 April 2019

\begin{abstract}
Leaf senescence is the last period of leaf growth and a dynamic procedure associated with its death. The adaptability of the plants to changing environments occurs thanks to leaf senescence. Hence, transcriptional profiling is important to figure out the exact mechanisms of inducing leaf senescence in a particular crop, such as rice. From this perspective, leaf samples of two different rice genotypes, the brown midrib leaf $(\mathrm{bml})$ mutant and its wild type (WT) were sampled for transcriptional profiling to identify differentially-expressed genes (DEGs). We identified 2670 DEGs, among which 1657 genes were up- and 1013 genes were down-regulated. These DEGs were enriched in binding and catalytic activity, followed by the single organism process and metabolic process through gene ontology (GO), while the Kyoto Encyclopedia of Genes and Genomes (KEGG) pathway analysis showed that the DEGs were related to the plant hormone signal transduction and photosynthetic pathway enrichment. The expression pattern and the clustering of DEGs revealed that the WRKY and $N A C$ family, as well as zinc finger transcription factors, had greater effects on early-senescence of leaf compared to other transcription factors. These findings will help to elucidate the precise functional role of $b m l$ rice mutant in the early-leaf senescence.
\end{abstract}

Keywords: rice; bml (brown midrib leaf); transcriptional analysis; DEGs; GO; KEGG; KOG; cluster analysis

\section{Introduction}

Leaf senescence is the ending period of leaf growth in the vegetative cycle, and acts as an indicator of physiological maturity of the harvest product. However, premature leaf senescence may mislead the growers to harvest too early. Many reports have pointed out that it plays adaptive roles in plants in changing environments by fine tuning the regulatory genes [1,2]. The majority of these genes are involved in (1) recycling and re-using the nutrients from senescent leaves for newly developed organs, and (2) enhancing tolerance against biotic or abiotic stresses [3-5].

Leaf senescence is a vital agronomic attribute for crop yield and quality [6-8]. A wide range of physiological processes occur in the leaves during the process of senescence. The rate of assimilation reduces more rapidly with the increase of catabolism, such as degradation of the chloroplast, reducing photosynthesis, and the degradation of macromolecules [9]. The senescence process might also be affected by internal as well as the external factors. The latter case is environmental conditions, e.g. soil moisture, light, temperature, nutrient content and pathogens $[10,11]$. Therefore, it is important to understand the internal factors that are responsible for leaf senescence, as this knowledge could help 
to elucidate the basic molecular mechanism. Exploration of that mechanism will provide a means for controlling leaf senescence in crop plants [2].

Many studies have been carried out on senescence-associated genes (SAGs) in different plant species [9,12-14], and currently, the database of leaf senescence comprises some 130 SAGs [15]. However, the findings have not provided a complete explanation of the molecular mechanisms of leaf senescence in monocots like, rice, wheat, maize, sorghum and barley. It has been established that the chlorophyll $(\mathrm{Chl})$ metabolism and degradation pathways are involved in several SAGs of leaf senescence [16]. During chlorophyll degradation, Chlb is changed to Chla in the first leaf, wherein NYC1 [17] and NOL [18] are involved in chlorophyll-b degradation. In A. thaliana, the gene PAO (Pheophorbide A Oxygenase) takes part in the degradation of chlorophyll, leading to leaf senescence [19]. $P P R$ (pentatricopeptide repeat) genes control chloroplast gene expression, and eventually, senescence of leaves in rice [20]. Plant hormones like MeJA (methyljasmonate) and JA (jasmonate) have been recognized as leaf senescence enhancing substances for rice [21]. The gene OsCOL1b (CORONATINE INSENSITVE 1b) encodes the JA receptor of Arabidopsis, and the mutant Oscoilb delays leaf senescence and shows insensitivity to MeJA [22]. Two important genes, OsPME and OsTSD2 [23], encode pectin-esterase and methyltransferase respectively were identified through mGWAS (metabolite-based genome-wide association study) [23]. Besides JA, IAA also plays a complex role in leaf senescence regulation. Leaf senescence can be delayed by exogenous IAA application [24]. Leaf senescence could be positively regulated by auxin-responsive genes such as SAUR (small auxin-up RNA) [24-27]. The gene OsPLS1 encodes a vacuolar $\mathrm{H}^{+}$-ATPase subunit $\mathrm{A} 1$, and negatively regulates leaf senescence at the beginning [28].

Leaf senescence in rice is regulated by several transcription factors (TFs); many of them belong to WRKY transcription factor [29,30]. In Arabidopsis, the AtWRKY70, AtWRKY53, AtWRKY54 genes are engaged in the signaling pathway of SA [31] which induces cell death and leaf senescence [30-32]. The over-expression of OsWRKY 42 exhibits ROS accumulation and accelerates leaf senescence through repressing OsMT1d in rice [33]. The chlorophyll metabolic pathway involved several GATA-zinc finger TFs, like GNC (GATA nirate-inducible carbon-metabolism) [34], degrades the chlorophyll in $A$. thaliana $[34,35]$. The over-expression of OsGATA12 reduces degradation of chlorophyll and delays leaf senescence, reducing the number of leaves and tillers, as well as enhancing yields in rice [36]. In addition, the GPC-B1 (grain protein content-B1) and OsNAC106 (N-acetylcysteine106) genes are senescence-linked transcription factors [37]. Among them, GPC-B1 accelerates leaf senescence [37], while ONAC106 regulates leaf senescence inversely [38]. The transporter family genes OsSWEET5 (sugar transporter family5) [39] and Yr18/Lr34/Pm38 from the ABC-transporter family also induce leaf tip senescence [40] in rice.

Transcriptomic analysis will help to identify the genes associated with leaf senescence, because the transcriptional profiling of the leaf senescence genes in rice is still under exploration. Therefore, the identification of these genes through RNA-Seq (RNA sequencing) is crucial to understanding the molecular mechanisms of leaf senescence and to developing stress-adaptive rice cultivars in order to achieve higher yields. RNA-Seq is a quantification technology of transcripts which provides precise levels of transcripts measurements; therefore, it has been successfully and widely used for profiling transcripts with annotations, and in the identification of genes in different plant species [41-46].

In the present study, RNA-sequencing analysis was accomplished with a mutant of early-leaf senescence, $b m l$ mutant, and its WT variety, Zhenong 34 , at an early-tillering stage. In our previous study, this $b m l$ mutant was identified and reported in the mutational rice population developed by ethyl methane sulfonate (EMS) mutagenesis. Such a mutant was differentiated by the phenotypic character of the early-senescence in leaf from the $\mathrm{M}_{2}$ population [47]. Herein, we performed transcriptomic profiling of that $b m l$ mutant Vs WT to identify the differentially-expressed genes and post-translation modifications in order to elucidate the mechanisms involved in leaf senescence. GO enrichment, Kyoto Encyclopedia of Genes and Genomes (KEGG) pathway and KOG/COG (Clusters of Orthologous 
Groups) analyses were also performed at an early-tillering stage. This transcriptome data will provide information necessary to understand leaf senescence in rice.

\section{Results}

\subsection{Phenotypic Characterization}

No observable differences were found between the $\mathrm{bml}$ mutant and WT in the seedling to tillering stage [47]. Senescence was found to start in the bottom leaves at the early-heading stage in the $b m l$ mutant, wherein the other leaves then became yellow with progressive senescence (Figure 1A). The midrib of the leaves in the $b m l$ mutant started to turn brown, and lesion phenotypes appeared on the leaf blade, gradually covering the whole leaf (Figure 1A,B). Leaf senescence was accelerated more in the $b m l$ mutant during the late-heading and grain filling stages, compared to WT. Our previous study showed that the $b m l$ plants demonstrated slower growth, with significantly reduced numbers of tillers, shorter panicle lengths, lower seed-settings, fewer grains in the panicles, lower 1000-grain weights, and smaller seed sizes (length and width) compared to WT [47].

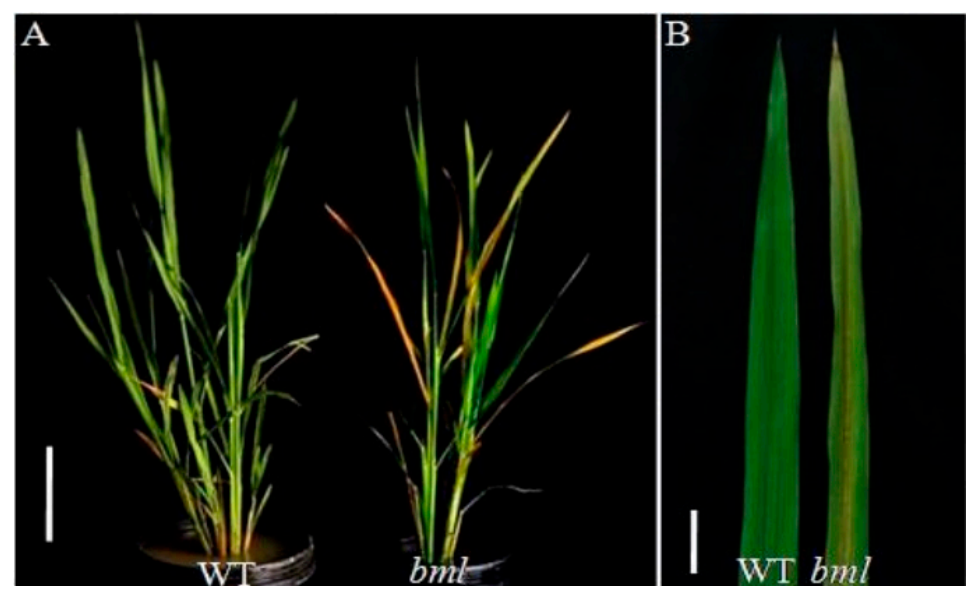

Figure 1. Phenotypes of bml mutant and WT rice plants. (A). Phenotype observed at the heading stage in bml mutant compared to WT. Bar $=10 \mathrm{~cm}$. (B). Magnified view of the part of flag leaf from the top of the plant displayed in A. Bar $=5 \mathrm{~cm}$.

Moreover, genetic analysis indicated that the early-senescence of leaf was controlled by a single recessive gene [47]. The mutants showed abnormal leaf cells with degraded chloroplasts and less chlorophyll, a reduced photosynthetic rate $\left(\mathrm{P}_{\mathrm{n}}\right)$, less stomatal conductance $(\mathrm{Gs})$ and intercellular $\mathrm{CO}_{2}$ concentration $(\mathrm{Ci})$, reduced transpiration rate (Tr) and $\mathrm{Fv} / \mathrm{Fm}$ (maximal quantum yield of PSII) compared to WT at the heading stage [47].

\subsection{RNA-Seq Analysis}

RNA-seq was performed for the transcriptomic profiling of $b m l$ mutant using leaf samples collected from three replicates of $b m l$ mutant and WT plants. The cDNA of WT and $b m l$ leaf samples were sequenced using Illumina technology to determine the probable DEGs and the pathways involved in the process of early-leaf senescence in the $b m l$ mutant. On average, 60,545,108 bp and 62,982,574 bp raw reads were retrieved from the RNA-seq data for the $b m l$ mutant and WT, respectively (Table 1). After removing the adaptor, ambiguous nucleotides, and low-quality sequences, approximately $56,637,709 \mathrm{bp}$ and $61,147,444 \mathrm{bp}$ clean reads were obtained from the WT and $\mathrm{bml}$ mutant, respectively, which covered an average length of 147.1 to $147.5 \mathrm{bp}$. The GC content of the clean reads ranged from 54.71 to $55.60 \%$ in different libraries, and the Q30 percentage exceeded 94.9\% (Table 1).

A total of 110,715,792 clean reads were generated by sequencing six cDNA libraries. All reads were classified into three categories: total mapped, multiple mapped and uniquely mapped. Of all 
the reads, $94.01-94.27 \%$ read were totally mapped, $91-93 \%$ were uniquely mapped, and $2-3 \%$ were mapped in the genome (Table 2). A summary of the sequencing data, alignment statistics of the reads to the reference gene, alignment statistics to reference genome and $\mathrm{QC}$ items for each sample are given in Tables 1 and 2.

A correlation of a heat map was constructed using the correlation coefficients of replicated samples of the $b m l$ mutant and WT (Figure 2). The correlation coefficient among $b m l$ samples was 0.95 (bml1, bml2 and bml3), while that among the WT samples was 0.94 (WT1, WT2 and WT3), which had a tendency for unity. These results revealed that the $b m l$ group ( $b m l 1, b m l 2$ and $b m l 3)$ differed significantly from the WT group (WT1, WT2 and WT3).

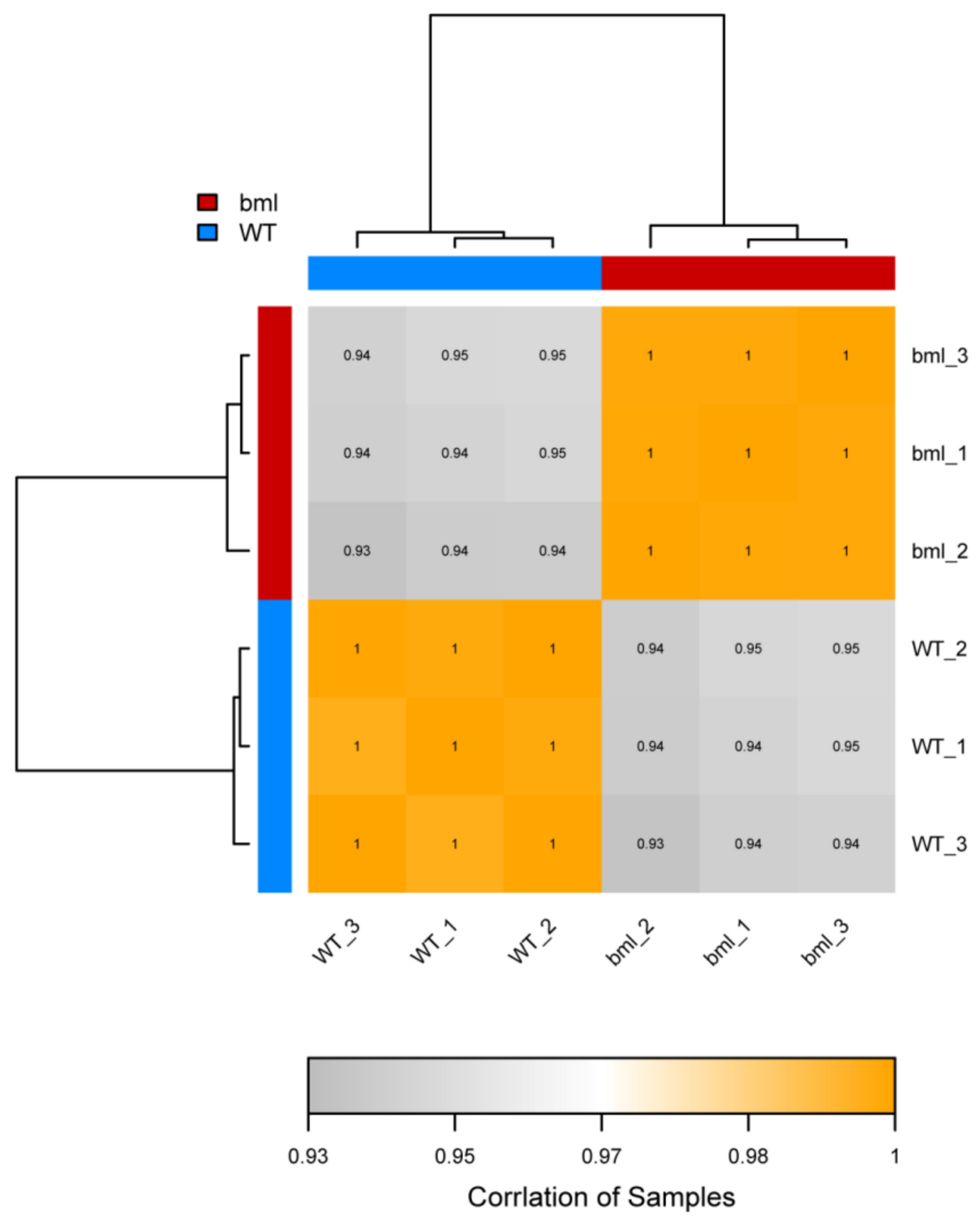

Figure 2. Heat-map diagram of inter-sample correlation analysis. The color block represents the correlation index value. The grayer the color, the lower the correlation index between samples and higher intensity of the color represents the higher correlation coefficient. 
Table 1. Reads summary of samples by Illumina deep RNA sequencing.

\begin{tabular}{|c|c|c|c|c|c|c|c|c|c|}
\hline $\begin{array}{l}\text { Sample } \\
\text { Name }\end{array}$ & $\begin{array}{l}\text { Raw } \\
\text { Reads }\end{array}$ & $\begin{array}{l}\text { Average Raw } \\
\text { Read Length } \\
\text { (bp) }\end{array}$ & $\begin{array}{l}\text { Clean } \\
\text { Reads }\end{array}$ & $\begin{array}{l}\text { Average Clean } \\
\text { Read Length } \\
\text { (bp) }\end{array}$ & $\begin{array}{l}\text { Clean Base } \\
\text { (bp) }\end{array}$ & $\begin{array}{l}\text { Error } \\
(\%)\end{array}$ & $\begin{array}{l}\text { Q20 } \\
\text { (\%) }\end{array}$ & $\begin{array}{l}\text { Q30 } \\
(\%)\end{array}$ & $\begin{array}{c}\text { GC } \\
\text { Content } \\
(\%)\end{array}$ \\
\hline WT & $60,545,108$ & 150 & $56,637,709$ & 147.10 & 30,965 & 0.00 & 98.44 & 94.64 & 54.71 \\
\hline$B m l$ & $62,982,574$ & 150 & $\begin{array}{c}61,147 \\
444\end{array}$ & 147.50 & 43,180 & 0.00 & 98.59 & 94.99 & 55.60 \\
\hline
\end{tabular}

Table 2. Alignment statistics summary of RNA-seq and mapping results.

\begin{tabular}{cccccccc}
\hline $\begin{array}{c}\text { Sample } \\
\text { Name }\end{array}$ & $\begin{array}{c}\text { Total } \\
\text { Reads }\end{array}$ & $\begin{array}{c}\text { Total } \\
\text { Mapped } \\
\mathbf{( \% )}\end{array}$ & $\begin{array}{c}\text { Multiple } \\
\text { Mapped } \\
\mathbf{( \% )}\end{array}$ & $\begin{array}{c}\text { Uniquely } \\
\text { Mapped } \\
\mathbf{( \% )}\end{array}$ & $\begin{array}{c}\text { Non-Splice } \\
\text { Reads (\%) }\end{array}$ & $\begin{array}{c}\text { Splice } \\
\text { Reads (\%) }\end{array}$ & $\begin{array}{c}\text { Reads Mapped } \\
\text { in Proper Pairs } \\
\text { (\%) }\end{array}$ \\
\hline WT & 53579398 & 94.01 & 3.00 & 91.00 & 61.46 & 29.55 & 87.31 \\
$b m l$ & 57136394 & 94.27 & 2.56 & 93.45 & 63.36 & 28.33 & 88.06 \\
\hline
\end{tabular}

The average numbers of SNPs were 96,368 and 96,228 in the bml mutant and WT respectively, whereas INDELs were 10,861 and 11,020, respectively. SNP-affected regions were divided into two categories, i.e., genic (UTR and CDS) and inter-genic regions. A major part of the SNP-affected regions was covered by the genic region for both the $b m l$ mutant and WT (Table S2). Two kinds of nucleotide substitutions were identified at homozygote polymorphic SNPs due to transversions (A/C, A/T, C/G, $\mathrm{G} / \mathrm{A}$ and $\mathrm{G} / \mathrm{T}$ ) and transitions (A/G, G/A, T/C and C/T). The occurrence of SNPs in transitions was more frequent for both the $b m l$ mutant and the WT (Table S3).

\subsection{Identifications of DEGs}

The DEGs between $b m l$ mutant and WT were figured out at the early-tillering stage to explore the genes involved in leaf senescence of $b m l$ mutant (Table S4). A volcano plot of all genes was drawn to characterize the distribution of DEGs in the selection at threshold level (Figure 3A). A total number of 2670 DEGs was identified, among them 1657 genes were up-regulated and 1013 genes were down-regulated in $b m l$ Vs WT leaf. Moreover, we also detected the specific DEGs by the Venn diagrams and found 1858 genes as commonality in all the samples (Figure 3B).

\subsection{GO Enrichment Analysis}

Gene Ontology (GO) is an international standardized gene functional classification system that defines the genes according to three terms: molecular function, cellular component and biological process. The enriched GO terms of down- and up-regulated DEGs was analyzed and presented as bar-plot. A total 16,510 genes was assigned in GO and 1503 (9.10\%) DEGs annotated significantly in the GO database, among them 537 and 966 genes were regulated down- and up-, respectively. These genes were assigned to 50 subcategories (Figure 4 and Table S5). Among them, a majority of the genes were categorized as biological process $(44.89 \%)$ followed by molecular $(32.65 \%)$ and cellular functions (24.48\%) (Figure 4 and Table S5). A higher proportion of the genes were involved in biological function because the leaf senescence is a physiological process, which could bring the changes in many biological processes and regulated by the genes and perceived the signals in the early-tillering stage for enhancing the leaf senescence at early heading stage. In the category of biological process, the majority of the genes were assigned in the metabolic subcategory followed by single organism and cellular process. A significant proportion of the clusters were classified as binding, followed by catalytic activity with transcription factor activity and sequence specific DNA binding but no RNA binding in the molecular function category (Figure 4). 
$\mathbf{A}$

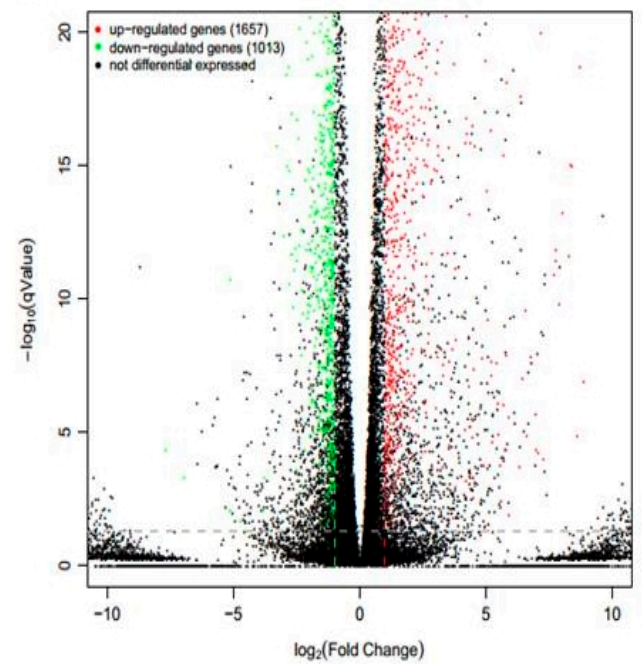

B

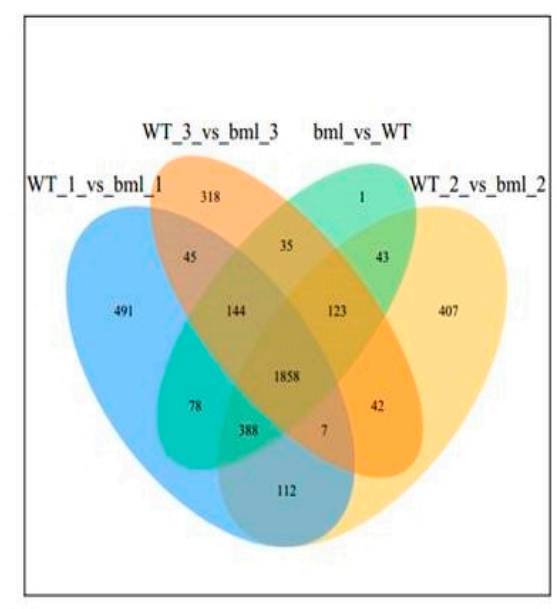

Figure 3. Volcano map and Venn diagram of DEGs. (A). DEGs are shown by volcano map between $b m l$ and WT at early-tillering stage. The horizontal axis is the fold-change $\left(\log _{2}(\mathrm{~B} / \mathrm{A})\right)$ value of the differential expression of the gene in different groups of samples, and the vertical axis is the statistical significance level with $\mathrm{p}$ value representing the changes in gene expression. Each point in the figure represents a gene, in which red indicates up-regulated genes, green indicates down-regulated genes, and black indicates non-differentiated genes. (B). DEGs between $b m l$ mutant and WT at early-tillering stage are plotted by Venn diagram. The comparison between different groups is represented by different colors, and the numbers in the figure represent the number of specific or shared DEGs. The overlap region indicates the number of differentially expressed genes shared by different comparison groups, and the non-overlapping region indicates the number of DEGs unique between the different comparison groups.

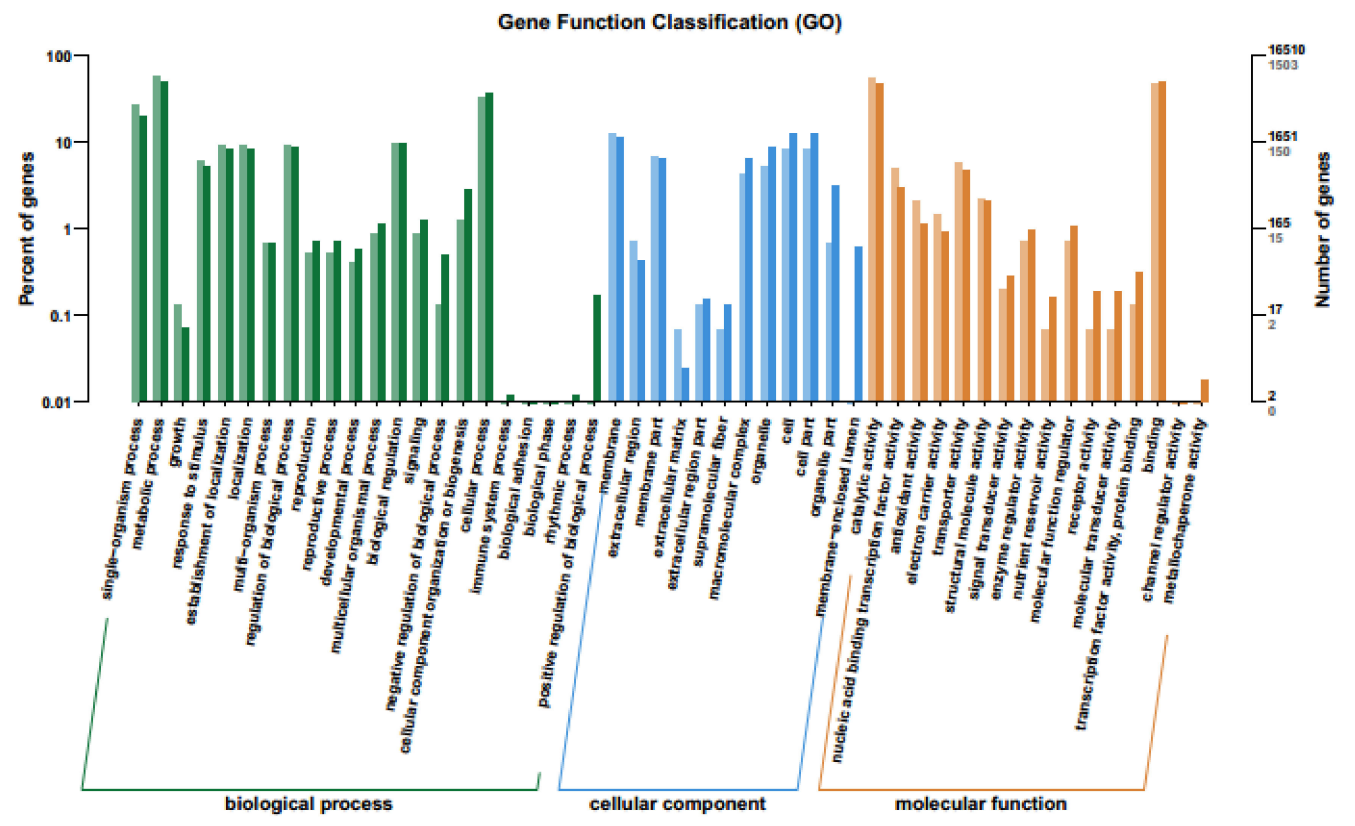

Figure 4. Differential gene ontology (GO) analysis of functional enrichment with up- and down-regulated DEGs between $b m l$ mutant and WT at early-tillering stage. The horizontal axis is the functional classification and the vertical axis is the number of genes in the classification (right) and the percentage of the total number of genes on the annotation (left). Different colors represent different classifications. Light colors on the histogram and axis represent differential genes, and dark colors represent all genes. 
For cellular component subcategory, the largest portion of the genes was subcategorized as the involvement in membrane followed by cell with cell part, membrane part and organelle part. A few genes were assigned to the rhythmic process, immune system process, extracellular matrix and mettalochaperon activity categories. The scatter plot of the DEGs (up- and down-regulated) also showed that maximum number of DEGs involved in binding and catalytic activity followed by the single organism process and the single organism metabolic process (Supplementary Figure S1).

\subsection{KEGG and KOG Pathway Analysis of DEGs}

KEGG analysis with DEGs was executed for further investigating the pathway involved in leaf senescence of the $b m l$ mutant at the early-tillering stage. The unigenes orientations of metabolic pathways were investigated through bar-plot analysis in the KEGG database. Among 5226 assigned genes, only 527 genes were found to be involved in five pathways, such as the cellular, environmental and genetic information processing as well as in the metabolism and organismal systems (Figure 5A and Table S6).
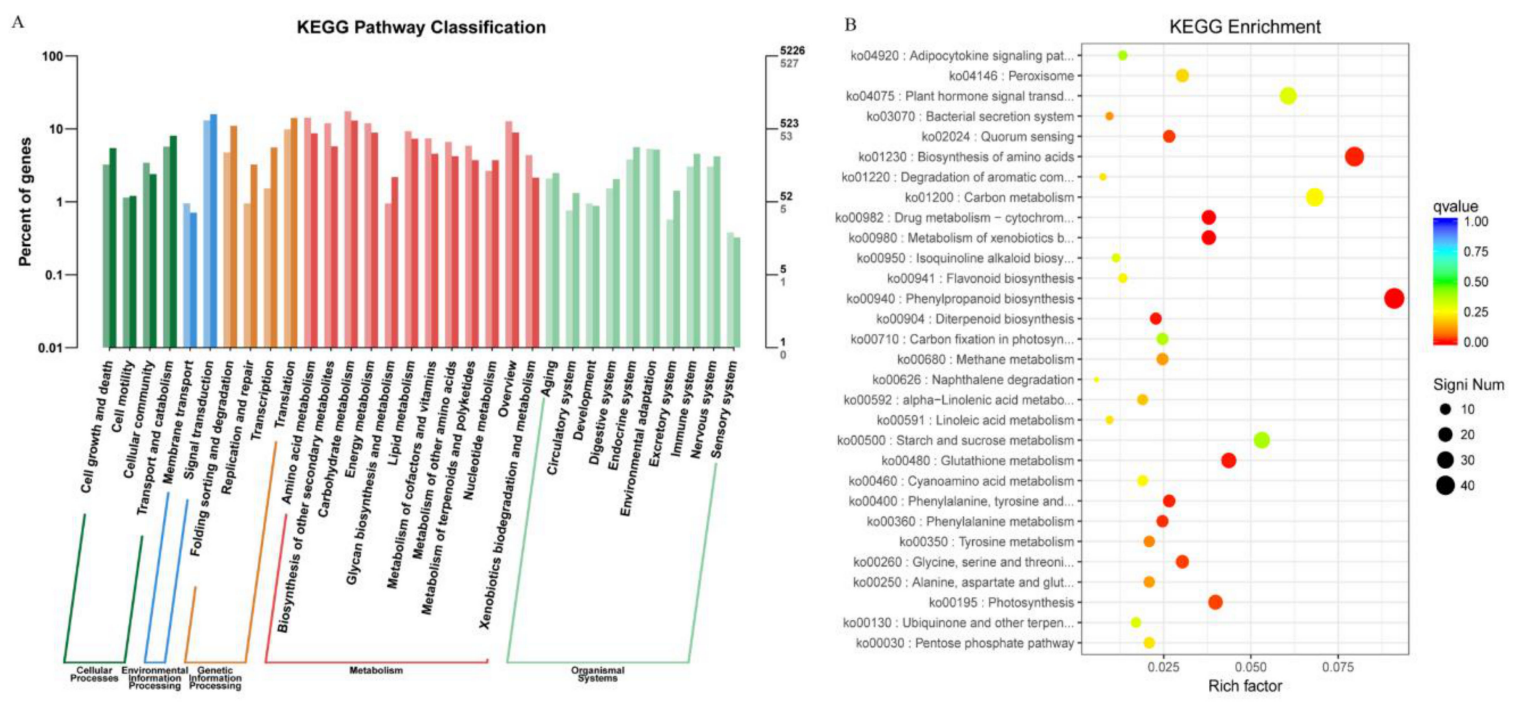

Figure 5. KEGG (Kyoto encyclopedia of genes and genomes) analyses of DEGs between $b m l$ and WT at early-tillering stage by barplot and scatter diagram. (A). KEGG analysis of DEGs through barplot. The horizontal axis is the functional classification, and the vertical axis is the number of genes in the classification (right) and the percentage of the total number of genes on the annotation (left). Different colors represent different classifications: light colors on the histogram and axis represent differential genes, and dark colors represent all genes. (B). Scatter plot of significant enrichment function. The vertical axis represents functional annotation information, and the horizontal axis represents the function of the Rich Factor (the number of differential genes annotated to the function divided by the number of genes annotated to the function). The size of the $Q$ value is represented by the color of the dot; the smaller the $Q$ value, the closer the color is to red, and the more the differential genes contained under each function are represented by the size of the dots. Only the top $30 \mathrm{GOs}$ with the highest levels of enrichment were selected.

The scatter plot analyses of the significant KEGG enrichment showed the function and highly differentially expressed genes are represented by the size of the dots upon each function (Figure 5B and Table S7). Here, we selected only top 30 KEGGs based on the highest level of KEGG enrichment. Among them, ko04075 (plant hormone signal transduction), ko01230 (biosynthesis of amino acid), ko00940 (phenylpropanoid biosynthesis), ko00710 (carbon fixation in photosynthetic organisms), ko00195 (photosynthesis) and ko00480 (glutathione metabolism) DEGs had significant enrichment in KEGG pathways related to the leaf senescence. It also indicated that the genetic signal of early leaf 
senescence might be perceived in the earlytillering stage of $b m l$ mutant plants through alteration of hormonal signal transduction and photosynthesis.

The most relevant biological pathways for early-leaf senescence of the $b m l$ mutant could be identified by enrichment analysis. Functions of uniqueness were classified according to COG/KOG databases using orthologous gene products. A total of 10106 non-redundant uni-genes was found in KOG analysis, among which 929 genes showed differential expression. Unique DEGs were divided into $26 \mathrm{KOG}$ sub-functional groups (Figure 6); it was determined that the maximum of them was involved in the signal transduction mechanism followed by general function prediction, post-translational modification, protein turnover and chaperone with secondary metabolite biosynthesis, transport, as well as catabolism. Few unique DEGs were found to involve in cell motility.

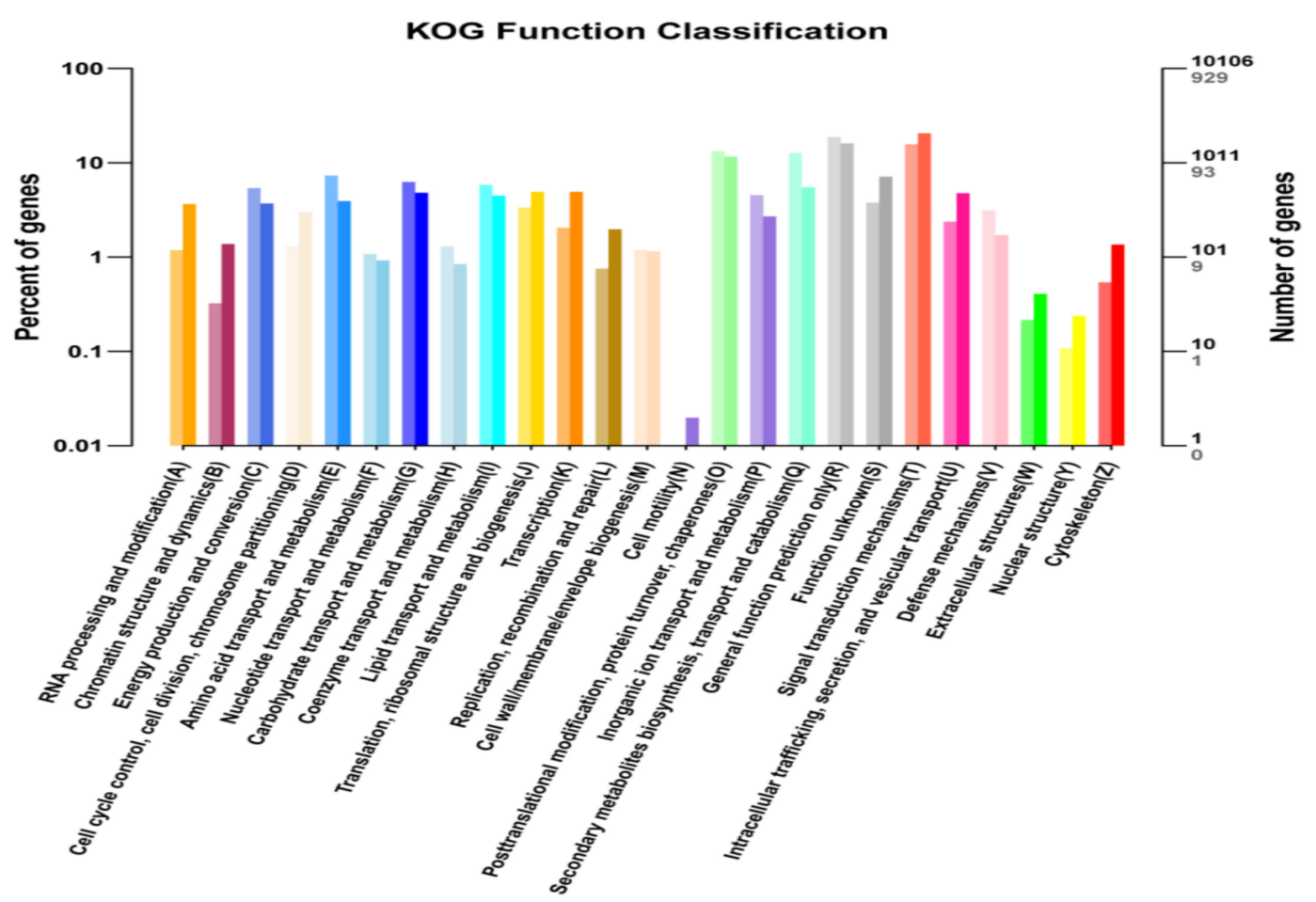

Figure 6. KOG/COG (Clusters of Orthologous Groups) analyses of DEGs between $b m l$ mutant and WT at early-tillering stage. The horizontal axis is the functional classification, and the vertical axis is the number of genes in the classification (right) and the percentage of the total number of genes on the annotation (left). Different colors represent different classifications. Light colors on the histogram and axis represent differential genes, and dark colors represents all genes.

\subsection{Confirmation of Gene Expression Profile through $q R T-P C R$}

The qRT-PCR was executed to validate the RAN-seq data using 25 randomly selected genes relevant to leaf senescence (Table 3). The gene expression pattern was similar to the transcriptome data of RNA-seq (Table 3), indicating the consistency and reliability of the transcriptomes. 
Table 3. Relative expression of 25 randomly-selected genes for comparison between the $b m l$ mutant and WT group with respect to RNA- seq and qRT PCR.

\begin{tabular}{|c|c|c|c|c|c|}
\hline \multirow{2}{*}{ Gene ID } & \multirow{2}{*}{ Gene Name } & \multicolumn{2}{|c|}{ bml vs. WT } & \multirow{2}{*}{ Gene Description } & \multirow{2}{*}{ Pathway/Function Involved } \\
\hline & & RNA-Seq $\log _{2}$ Fold Change & qRT PCR Fold Change & & \\
\hline LOC_Os01g12710 & NYC1 & -1.509 & $-0.880 \pm 0.02$ & NAD(P)-binding Rossmann-fold superfamily protein & $\begin{array}{l}\text { Porphyrin and chlorophyll } \\
\text { metabolism }\end{array}$ \\
\hline LOC_Os02g52650 & LHCA5 & -1.266 & $-569 \pm 0.207$ & Photosystem I light harvesting complex gene 5 & Photosynthesis-antenna proteins \\
\hline LOC_Os09g26810 & LHCA2.1 & -1.0265 & $-0.879 \pm 0.0890$ & Photosystem I light harvesting complex gene 6 & Photosynthesis-antenna proteins \\
\hline LOC_Os06g44010 & ATWRKY 40 & 3.722 & $3.455 \pm 0.418$ & WRKY DNA-binding protein 40 & WRKY transcription factor \\
\hline LOC_Os12g02470 & ATWRKY 53 & 6.512 & $5.360 \pm 0.1837$ & WRKY family transcription factor & WRKY transcription factor \\
\hline LOC_Os11g02540 & ATWRKY70 & 4.669 & $2.862 \pm 0.2069$ & WRKY DNA-binding protein 70 & WRKY transcription factor \\
\hline LOC_Os07g04560 & anac042 & 1.566 & $2.641 \pm 0.0344$ & NAC domain containing protein 42 & NAC transcription factor \\
\hline LOC_Os10g42130 & anac071 & 2.630 & $2.798 \pm 0.0182$ & NAC domain containing protein 71 & NAC transcription factor \\
\hline LOC_Os09g 36200 & ATNYE & 1.437 & $1.375 \pm 0.0246$ & Non-yellowing 1 & NAC transcription factor \\
\hline LOC_Os01g21250 & AtLEA5 & 4.182 & $3.947 \pm 0.0286$ & Senescence-linked gene 21 & Biological process \\
\hline LOC_Os03g0529 & SAG12 & 1.043 & $3.139 \pm 0.0128$ & Senescence-associated gene 12 & Proteolysis (Biological process) \\
\hline LOC_OS06g 16370 & ATCOL2 & -2.334 & $-0.194 \pm 0.0378$ & CONSTANS-like 2 & GATA transcription factor \\
\hline LOC_Os03g08330 & JAZ10 & 1.336 & $0.893 \pm 0.0239$ & Jasmonate-zim-domain protein 1 & Plant hormone signal transduction \\
\hline LOC_Os01g09450 & IAA26 & -3.341 & $-1.985 \pm 0.0462$ & Phytochrome-associated protein 1 & Plant hormone signal transduction \\
\hline LOC_Os02g57250 & IAA13 & -1.316 & $-0.639 \pm 0.0302$ & Auxin-induced protein 13 & Plant hormone signal transduction \\
\hline LOC_Os01g28450 & ATPR1 & 6.095 & $5.015 \pm 0.0108$ & Pathogenesis-related gene 1 & Plant hormone signal transduction \\
\hline LOC_Os07g03730 & PR1a & 10.420 & $4.106 \pm 0.105$ & Pathogenesis-related gene 1 & Plant hormone signal transduction \\
\hline LOC_Os01g09800 & ATNPR1 & 1.140 & $1.893 \pm 0.1017$ & Pathogenesis-related gene 1 & Plant hormone signal transduction \\
\hline LOC_Os04832480 & JAZ5 & 3.746 & $2.084 \pm 0.143$ & Jasmonate-zim-domain protein 10 & Plant hormone signal transduction \\
\hline LOC_Os09g29660 & ABCG11 & 1.868343 & $1.901 \pm 0.041$ & $\mathrm{ABC}$ super family & $\mathrm{ABC}$ transporter \\
\hline LOC_Os07g48260 & ATWRKY54 & 3.980698 & $4.035 \pm 0.051$ & WRKY DNA-binding protein 54 & WRKY transcription factor \\
\hline LOC_Os01g60700 & ATSIK & 1.036138 & $1.241 \pm 0.312$ & Serine/threonine protein kinase & Protein kinase superfamily protein \\
\hline LOC_Os04g33630 & ATFD3 & -1.74014 & $-0.934 \pm 0.063$ & Ferredoxin 3 & Photosynthesis related \\
\hline LOC_Os09g36250 & AtMYB42 & 1.8693 & $1.012 \pm 0.082$ & MYB domain protein 42 & MYB domain transcripton factor \\
\hline LOC_Os04g43070 & AMT1;1 & 1.9946169 & $1.512 \pm 0.101$ & Ammonium transporter $1 ; 1$ & Ammonium transporter \\
\hline
\end{tabular}


bml showed the senescence and lesion mimic phenotype and functions related to hormone signaling and photosynthesis pathways and transcription factor genes. In this regard, we prioritized the identification of the differentially-expressed genes involved in early-leaf senescence (Table 3). In the early-leaf senescence of rice mutant $b m l$, DEGs were enriched in plant hormone signal transduction, photosynthesis, and photosynthesis with antenna proteins pathways including WRKY, NAC, GATA transcription factors, chlorophyll metabolism as well as different biological processes. We also identified 22 DEGs orthologs of the rice genes related to abscicic acid (ABA; 6 genes), indole acetic acid (IAA; 6 genes), jasmonic acid (JA; 2 genes), and salicylic acid (SA; 8 genes) responses (Table S4). Among them, the orthologs of IAA26 (LOC_Os02g57250) and IAA13 (LOC_Os01g09450) were down-regulated in the $b m l$ mutant. The relative expression of the genes of ABA signal transduction was increased in $b m l$ compared to WT. PR1 family-related genes are involved in the SA signaling pathway; therefore, we found that SA-related LOC_Os01g28450, LOC_Os01g09800 and LOC_Os07g03730 genes were significantly up-regulated in the $b m l$ mutant compared to WT. JA signaling genes, e. g. JAZ10 (LOC_Os03g08330) and JAZ5 (LOC_Os04g32480) were also up-regulated in the bml mutant (Table 3). The results confirmed that the gene expression was matched and steady with the transcript analysis accomplished through RNA-seq.

\subsection{Cluster Analysis of DEGs}

We performed a cluster analysis using the expression values of the DEGs to identify the genes directly connected to leaf senescence. Hierarchical clustering was performed considering $10 \%$ cut-off of the tree constructed from DEGs by the R package (Figure 7).

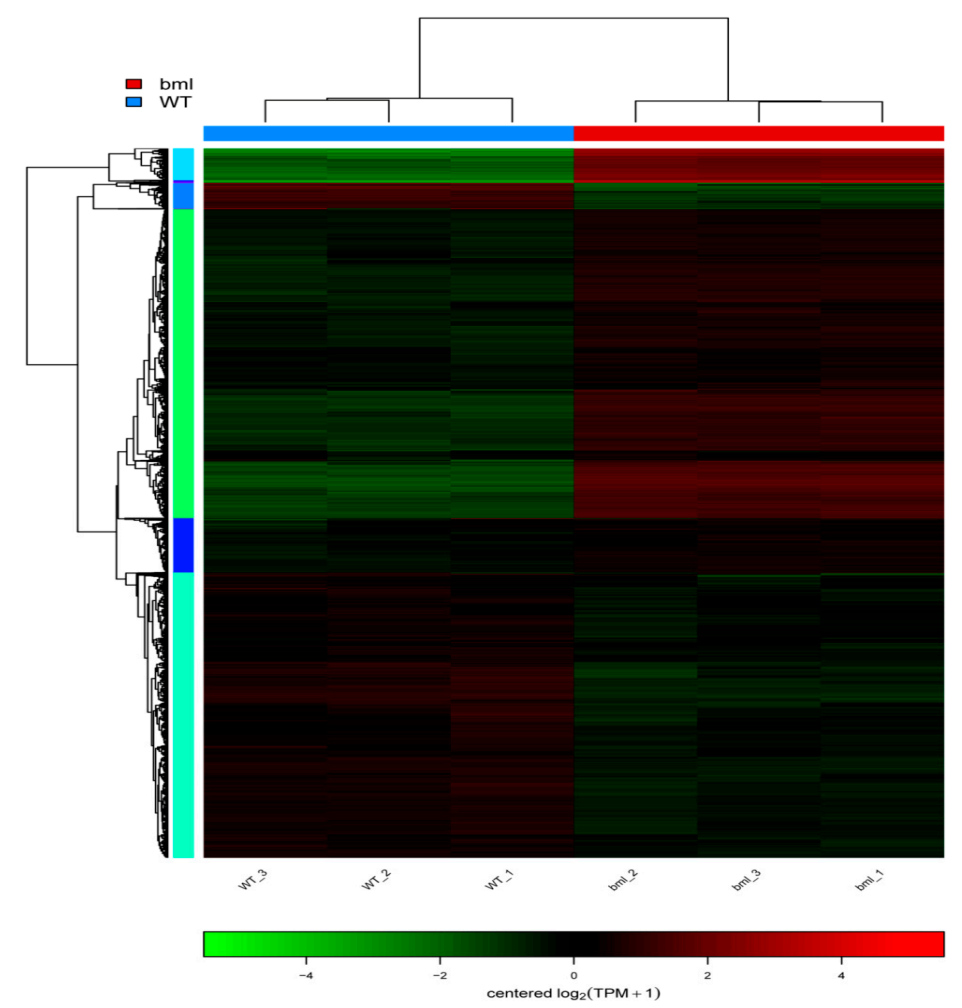

Figure 7. Clustering heat map of differential gene expression. Each row in the Figure represents a gene, each column represents a sample, and the color indicates the amount of expression of the gene in the sample. Red indicates that the gene is expressed in the sample, and green indicates that the expression level is low. The left side is a tree diagram of gene clustering. The closer the two gene branches are, the closer they are. The upper part is the tree diagram of the sample cluster, and the lower part is the name of the sample; the two samples are separated. The closer it is, the closer the expression patterns of all the genes in these two samples are, i.e., the closer the trend of gene expression changes. 
In total, 4101 genes which exhibited diverse expression patterns between the $b m l$ mutant and WT were classified into 10 sub-clusters, (Figure 8 and Table S8). Six clusters showed the changes of gene expression, while 4 exhibited genes with up-regulation, and 2 contained genes with down-regulation in $b m l$. We found that the genes presented in the clusters were associated with senescence, and most genes showed up-regulation in the $b m l$ mutant. Among the up-regulated genes, 139 encoded kinase family proteins, and 19 belonged to receptor-like genes. Additionally, 55 genes were annotated as transcription factors or DNA-binding factors, 17 with WRKY transcription factors, while the rest showed orthology to $b Z I P, N A C$ and zinc finger transcription factors (Table S8).

A

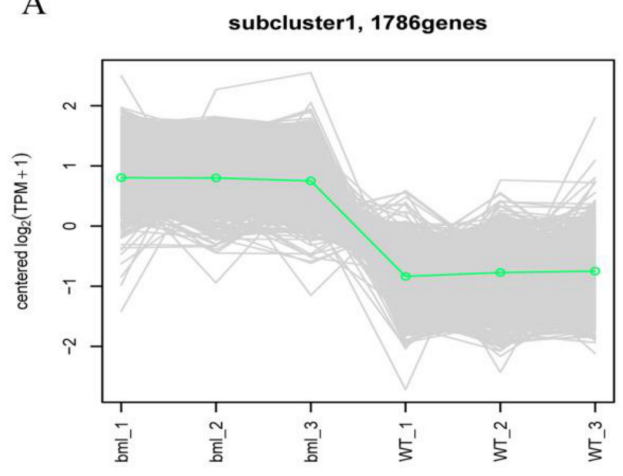

C

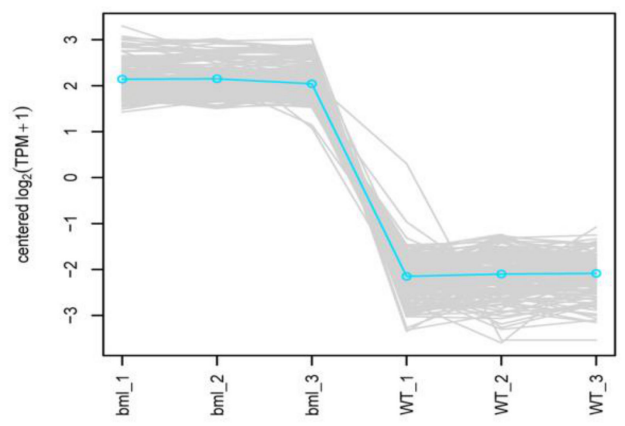

E

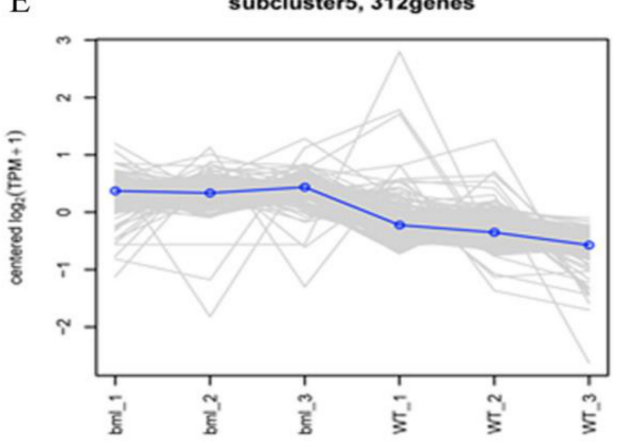

B

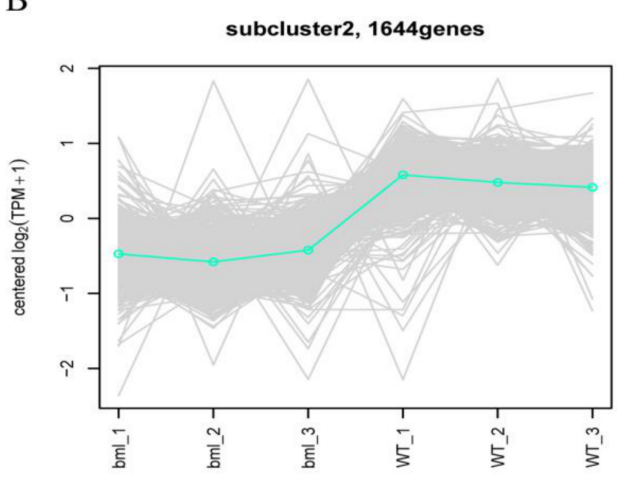

D

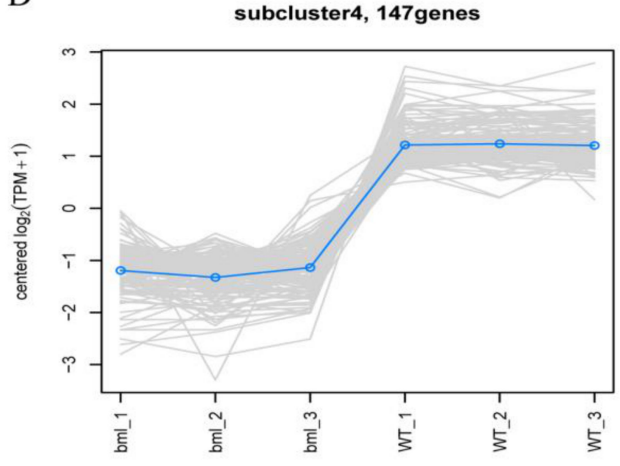

F
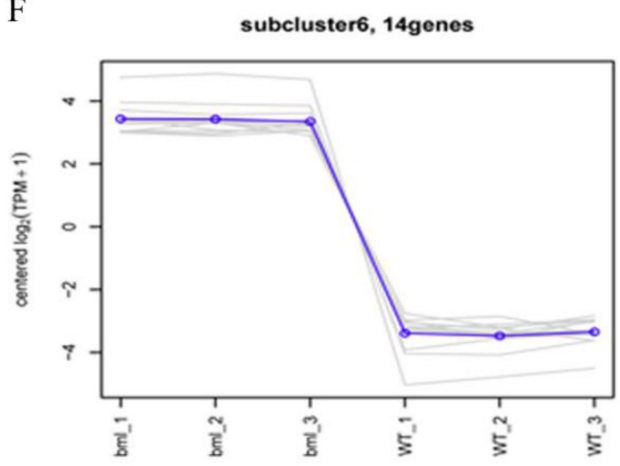

Figure 8. Differential gene module expression trends by the line chart. The expression trend line graph of each sub-module, the horizontal axis is the sample, and the vertical axis is the expression level of the gene in the sample. Each line in the figure represents a gene, and the colored lines represent the mean of a set of genes. Each graph shows one type of expression pattern, a trend that reflects changes in the expression levels of this group of genes; $(\mathbf{A}, \mathbf{C}, \mathbf{F})$ up-regulated pattern of gene in the $b m l$ mutants but down-regulated in WT, (B,D) up-regulated pattern of gene in the WT but down-regulated in $b m l$ mutants and (E) genes had no response due to mutation. 


\section{Discussion}

A rice mutant, $b m l$, showed the effect on plant growth and development. By genetic analysis, it was concluded that early-leaf senescence was governed by the recessive $b m l$ gene [47]. RNA-Seq analyses were performed to determine whether the changes of the transcriptome of senescence-associated genes, rather than solely the $b m l$ recessive gene, started at the beginning of tillering, by comparing the sequence data of $b m l$ and WT of rice at early-tillering stage. It was kept in mind that RNA-Seq analysis helps with precise the transcript profiling, annotation and identification of genes in plants $[41,43,46]$.

Most of the correlation coefficients of our $b \mathrm{ml}$ samples were 0.95 , while that of the WT samples was 0.94, which were approaching unity, indicating a higher level of similarity in the expression patterns among the samples [45]. These results revealed high sample repeatability, and reflected significant differences between the $b m l$ and WT groups.

A total of 25 genes were randomly selected from the identified DEGs for testing of their expression at the early-tillering stage by qRT-PCR. The qRT-PCR results showed that the genes were expressed differentially, and they confirmed the trustworthiness of our transcriptome data. The identification of DEGs in diverse transcripts was very important for finding the differentially-expressed genes between the samples, and for carrying out an additional functional analysis of the outcomes [45,48]. Among the 2670 DEGs, 1657 and 1013 genes showed up- and down-regulation respectively. About 50 enriched GO terms were detected by the GO enrichment analysis of the DEGs at the early-tillering stage. Moreover, KOG analysis of DEGs showed the involvement of uni-genes in the signal transduction mechanism, which is relevant to early-leaf senescence, and which was recognized at the early-heading stage; these results were confirmed by Zhang et al. [32]. Mainly, the WRKY transcription factor genes were significantly up-regulated in the $b m l$ mutant, indicating their direct involvement in early-leaf senescence. Similarly, the orthologous genes of AtWRKY40, AtWRKY53 and AtWRKY70 transcription factors were engaged in SA signaling transduction pathways in leaf senescence $[31,32,49]$.

The functional activity of WRKY transcription factors occurs in the upstream of the regulatory network of leaf senescence. By comparing the expression profiles of the differential genes of $b m l$ mutant and WT, we deduced that the gene encoded protein kinase WRKY transcription factor, GATA transcription factors, $b Z I P, N A C$ and zinc finger transcription factors play potential roles in the leaf senescence process, which is in agreement with a previous study by Leng et al. [5]. We also found that down-regulated DEGs were enriched in GO terms such as photosystem I, photosystem II and chlorophyll metabolism at the early-tillering stage (Table S5); those were reported as the factor of degenerative phase in earlier studies [50]. On the process of senescence, the leaf cells pass through a remarkable transition and systematic deterioration of different cellular structures [29]. We found several differentially-expressed genes in the $b m l$ mutant related to chlorophyll metabolism and which contribute to leaf senescence.

The expression of orthologs of chloroplast precursor-relative and TPR (tetratricopeptide repeat) like super family genes LOC_Os08g09270, LOC_Os06g02120 and LOC-Os01g25600 were down-regulated in the $b m l$ mutant (Table S4). In the $b m l$ mutant, the genes of grana degradation, photosynthesis pathway, photosystem I and photosystem II (Photosynthesis - antenna proteins pathway) were shown to be down-regulated, which supports our results by the down-regulation of NYC1, ATFD3, ATLFNR2, LHCA5 and LHCA2 genes [18,51,52] which causes early-leaf senescence. The orthologs of ATCOL2 (a GATA transcription factor) were down-regulated, which can influence leaf senescence by regulating chlorophyll accumulation $[35,36]$. Pentatricopeptide repeat (PPR) super family proteins can affect the content of chloroplast through regulating the gene expression of the chloroplast, e.g., OspTAC2 gene in rice [20] and other PPR, PPR53 genes might also change the gene expression of chloroplast and influence the development of leaf in maize [53]. We found several PPR-like genes in our transcriptome profiles, such as LOC_Os01g48380, LOC_Os06g07550, LOC_Os10g10170 and LOC_Os06g09880, which were down-regulated in the bml mutant and might play a role in the process of early leaf senescence in rice. 
KEGG pathway analysis showed that leaf senescence is affected by the plant hormone signaling pathway. A prior study reported that SA, JA, ABA and ET accelerate leaf senescence, while IAA, GA and CK were found to delay its development [54]. In the present study, we found IAA related genes, such as the LOC_Os02g57250 and LOC_Os01g09450 as orthologs of IAA26 and IAA13, respectively, were down-regulated in the $b \mathrm{ml}$ mutant. The expression of ABA hormone signal transduction pathway genes increased in the $b m l$ mutant. The PR1 family-related genes, such as LOC_Os01g28450,LOC_Os01g09800, and LOC_Os07g03730 involved in SA signaling pathway showed significant up-regulation in the $b m l$ mutant. JA signaling genes, such as JAZ10 (LOC_Os03g08330) and JAZ5 (LOC_Os04g32480), also showed up-regulation in the $b \mathrm{ml}$ mutant (Table 3), which should enhance leaf senescence. These results revealed that leaf senescence in the $b m l$ mutant might be controlled by different hormones, as stated in a previous study of wheat [32].

The cluster analysis of DEG expression patterns gave us an idea and the opportunity to classify and identify senesce-associated genes (SAGs) in rice. We gave more emphasis to clusters in which gene expression patterns showed obvious up- and/or down regulation in the $b m l$ mutant compared to WT (Figure 8 and Table S8). Many types of protein kinases genes, like receptor-like protein kinase, transcription factors and transporter proteins, were significantly enriched. The number of WRKY family, NAC and zinc finger transcription factor genes was higher than that of other transcription factor genes. A previous report revealed that many transcription factor genes were connected to leaf senescence in Arabidopsis [30], and might play significant roles in the early-senescence of rice. So, we concluded that signal transduction and substance transport were associated, and that the perceived the genetical signals at the early-tillering stage of $b m l$ rice plants contribute to early leaf senescence.

We explored and profiled the transcriptomes of $b m l$ mutant and WT plants at the early-tillering stage to determine and annotate the transcripts linked to leaf senescence. The GO enrichment, the KEGG pathway of DEGs and the KOG/COG were analyzed at the early-tillering stage. Multiple pathways were found to be involved in the leaf senescence process in rice. Among them, plant hormone signal transduction, photosynthesis, photosynthesis antenna protein pathways played predominant roles in the early leaf senescence process. These pathways' genes might be evacuated in chlorophyll break down or degradation; the accumulation of antioxidant activity and ROS molecules play a direct role in leaf senescence. Our results confirmed the transcriptional factor and signal transduction genes which bring about changes in the regulation of different hormones which accelerate the early senescence process of leaf in rice. Therefore, in our future breeding programs, we could emphasize those genes to ensure delayed senescence by increasing the duration of photosynthesis and higher yields in rice.

\section{Materials and Methods}

\subsection{Plant Materials}

Two rice genotypes, i.e., the wild form of Zhenong 34 and its mutant of brown midrib leaf $(\mathrm{bml})$ from Oryza sativa L. ssp. Indica, were used for RNA-sequencing. The $b m l$ is the mutant of Zhenong 34 produced by ethyl methane sulfonate (EMS) mutagenesis. The mutant plants were selected by gene mapping according to a bulk segregant analysis (BSA) method, as well as being differentiated phenotypically and recognized as early-senescence of leaf compared to WT in the $\mathrm{M}_{2}$ population [47]. Plants were grown in rice fields at the Zhejiang University in Hangzhou, China $\left(30^{\circ} 15^{\prime} 49^{\prime \prime} \mathrm{N}, 120^{\circ} 7^{\prime} 15^{\prime \prime}\right.$ E), during March-July 2017; the average temperature was $14^{\circ} \mathrm{C}$ to $33^{\circ} \mathrm{C}$, with 60 to $70 \%$ R.H. The leaf tissues were collected from the plant seedlings ( 25 days after sowing and just before transplanting), early tillering ( 15 days after transplanting) and early booting ( 45 days after sowing) stages, 10 leaves from 10 plants at same growing stage of the WT and $b m l$ plants were collected as biological replicates and pooled together before being immersed in liquid nitrogen. All samples were stored in a refrigerator at $-80^{\circ} \mathrm{C}$ until RNA extraction. 


\subsection{RNA Isolation, Library Preparation and Sequencing}

Total RNA was extracted using the total RNA Extractor (Trizol) kit (B511311, Sangon, China) according to the manufacturer's protocol. The quality and quantity of the extracted RNA were assessed using Agilent 2100 Bioanalyzer (Agilent Technologies, CA, USA) and NanoPhotometer ${ }^{\circledR}$ spectrophotometer (IMPLEN, CA, USA). High-quality RNA samples were subsequently submitted to the Sangon Biotech Co. Ltd., Shanghai, China for sequencing and library preparation.

The mRNA was purified from the total RNA using poly-T oligo-attached magnetic beads. Fragmentation was carried out using the divalent cations under an elevated temperature in a VAHTSTM First-Strand Synthesis Reaction Buffer $(5 \times)$. First strand cDNA was synthesized using a random hexamer primer and M-MuLV Reverse Transcriptase (RNase H-). Second strand cDNA synthesis was subsequently performed using DNA polymerase I and RNase $\mathrm{H}$. The remaining overhangs were converted into blunt ends via exonuclease/polymerase activities. After adenylation of the 3' ends of the DNA fragments, the adaptor was ligated in order to prepare the libraries. The adapter primer sequences were used as the forward primer: 5'AGATCGGAAGAGCACACGTCTGAAC3', and the reverse primer: 5'AGATCGGAAGAGCGTCGTGTAGGGA3'. The library quality was assessed on the Agilent Bioanalyzer 2100 system (Agilent Technologies). A total of six libraries, including three from the $b m l$ mutant and three from WT, were generated. Paired-end sequencing of the libraries was performed using an Illumina HiSeqTM2000 (Illumina, San Diego, CA, USA).

\subsection{Data Filtering, Reads Mapping and RNA-Seq Data Analysis}

Raw reads of primary sequencing were collected from the Illumina HiSeqTM 2000 and filtered (before downstream analysis for reducing data noise) to retrieve the clear reads. During the filtration of the data, adapter, poly- $\mathrm{N}$, as well as low-quality reads were removed from the raw data to ensure the reliability of the analysis. The clean reads were stored in the FASTQ format [55], and Bowtie 2 [56] was used to map clean reads to the reference gene. HISAT2 (version 2.1.0) [57] was used with the parameters: hisat2-mm-dta-p 10-x genome.fa-known-splicesite-infile genes.ss-1 R1.fastq.gz-2 R2.fastq.gz to align the clean reads with the reference genome of the Nipponbare subspecies of rice (Oryza_sativa.v7.0; http:/ / rice.plantbiology.msu.edu/) with an ideal match or one mismatch. RSEM, a precise and accessible software tool, was used to determine the transcript isoforms of the same gene [58].

\subsection{Transcriptomic Analysis}

DESeq2 (version 1.12.4) was used to determine the DEGs between two samples. Genes were considered as differentially- and significantly-expressed if $q$-value $<0.001$ and $\mid$ Fold Change $\mid>2$. Expression values of zero for the samples were treated as 0.01 during normalization, because zero could not be plotted onto the log plot.

Next, DEGs were mapped to the GO terms (biological functions) in the database, the number of genes was calculated in every term, and a hypergeometric test was performed to identify any significantly enriched GO terms for the genes list in the background of the reference list. KEGG pathway analysis identified significantly enriched metabolic pathways and signal transduction pathways in DEGs compared to a reference genome.

\subsection{Quantitative Real-Time PCR}

For RNA-seq data validation, 25 genes were randomly selected from DEGs and tested for their expression levels at the early-tillering stage using quantitative real time PCR (qRT-PCR). Gene-specific primers were designed using the Primer 5 software (Table S1), with the parameters of 100-500 bp PCR product size, $20 \pm 2$ bp primer length, melting temperature $50-62{ }^{\circ} \mathrm{C}$, GC content $40-60 \%$ and run in automatic search mode. The qRT-PCR was performed in the Roche light cycler 480 real-time system (Roche, Germany) using Ex TaqII (Takara, Tokyo, Japan) according to the manufacturer's instructions, 
with five technical replicates of $10 \mu \mathrm{L}$ reaction mixture. Then, $10 \mu \mathrm{L}$ reaction mixture was mixed with $5 \mu \mathrm{l} 2 \times$ quanti speed SYBR mix with $1 \mu \mathrm{L}(10 \mathrm{pmol})$ for each of the forward (F) and reverse (R) gene specific primers, $1 \mu \mathrm{L}$ template cDNA (50ng) and $2 \mu \mathrm{L}$ distilled-deionized water $\left(\mathrm{ddH}_{2} \mathrm{O}\right)$. qRT-PCR was performed following denaturation at $95^{\circ} \mathrm{C}$ for $30 \mathrm{~s}, 40$ cycles of denaturation at $95{ }^{\circ} \mathrm{C}$ for $5 \mathrm{~s}$, annealing at $55^{\circ} \mathrm{C}$ for $20 \mathrm{~s}$, and extension at $72{ }^{\circ} \mathrm{C}$ for $10 \mathrm{~s}$. To calculate the expression, the OsActin reference gene was used as an internal control [59]. The relative expression was calculated by the $2^{-\Delta \Delta C T}$ method [60] using the cq values normalized by the cq of the rice OsActin gene.

Supplementary Materials: Supplementary materials can be found at http:/ /www.mdpi.com/1422-0067/20/7/ 1708/s1.

Author Contributions: D.A. and C.S. designed and developed the experiments. D.A. performed the main experiments and drafted the manuscript. C.S. identified and provided the populations of the $b m l$ mutant for genetic study and gene mapping. R.Q., J.E. and X.J. helped to carry out the experiments and collected some data. U.K.N. analyzed the data and edited the manuscript. All authors have read and approved the final manuscript.

Funding: This study was supported by grants from the Science and Technology Office of Zhejiang Province (2012C12901-2, 2016C32G2010016 and 2016C02050-6) and a grant from National Key Research and Development of China (2017YFD0100300-5).

Acknowledgments: We thanked Jocelyn M. Losh (email: losh3478@pacificu.edu), College of Life Science, Zhejiang University, China for critical reviewing and editing the manuscript. Special Thanks to Li Junying, Analysis Centre of Agribiologic and Environmental Science, Lab of Electron Microscope, Zhejiang University, China for helping partial analysis of transcriptome data.

Conflicts of Interest: The authors declared no conflict of interest.

\section{References}

1. Schippers, J.H.; Schmidt, R.; Wagstaff, C.; Jing, H.-C. Living to die and dying to live: The survival strategy behind leaf senescence. Plant Physiol. 2015, 169, 914-930. [CrossRef] [PubMed]

2. Lim, P.O.; Woo, H.R.; Nam, H.G. Molecular genetics of leaf senescence in Arabidopsis. Trends Plant Sci. 2003, 8, 272-278. [CrossRef]

3. Buchanan-Wollaston, V.; Earl, S.; Harrison, E.; Mathas, E.; Navabpour, S.; Page, T.; Pink, D. The molecular analysis of leaf senescence-A genomics approach. Plant Biotechnol. J. 2003, 1, 3-22. [CrossRef] [PubMed]

4. Kim, J.; Woo, H.R.; Nam, H.G. Toward systems understanding of leaf senescence: An integrated multi-omics perspective on leaf senescence research. Mol. Plant 2016, 9, 813-825. [CrossRef] [PubMed]

5. Leng, Y.; Ye, G.; Zeng, D. Genetic dissection of leaf senescence in rice. Int. J. Mol. Sci. 2017, 18, 2686.

6. Gregersen, P.L.; Culetic, A.; Boschian, L.; Krupinska, K. Plant senescence and crop productivity. Plant Mol. Biol. 2013, 82, 603-622. [CrossRef] [PubMed]

7. Distelfeld, A.; Avni, R.; Fischer, A.M. Senescence, nutrient remobilization, and yield in wheat and barley. J. Exp. Bot. 2014, 65, 3783-3798. [CrossRef] [PubMed]

8. Bray, E.; BaileyYserres, J.; Weretilnyk, C. Responses to Abiotic Stress. In Biochemestry E Molecular Biology of Plants; Gruissem, W., Jones, R., Eds.; American Society of Plant Physiologists: Rockville, MD, USA, 2000; pp. 1158-1203.

9. Lira, B.S.; Gramegna, G.; Trench, B.; Alves, F.R.R.; Silva, É.M.; Silva, G.F.F.; Thirumalaikumar, V.P.; Lupi, A.C.D.; Demarco, D.; Purgatto, E. Manipulation of a senescence-associated gene improves fleshy fruit yield. Plant Physiol. 2017, 175, 77-91. [CrossRef]

10. Juvany, M.; Müller, M.; Munné-Bosch, S. Photo-oxidative stress in emerging and senescing leaves: A mirror image? J. Exp. Bot. 2013, 64, 3087-3098. [CrossRef]

11. Zhang, H.; Zhou, C. Signal transduction in leaf senescence. Plant Mol. Biol. 2013, 82, 539-545. [CrossRef] [PubMed]

12. Li, H.; Wang, G.; Liu, S.; An, Q.; Zheng, Q.; Li, B.; Li, Z. Comparative changes in the antioxidant system in the flag leaf of early and normally senescing near-isogenic lines of wheat (Triticum aestivum L.). Plant Cell Rep. 2014, 33, 1109-1120. [CrossRef]

13. Buchanan-Wollaston, V. The molecular biology of leaf senescence. J. Exp. Bot. 1997, 48, 181-199. [CrossRef]

14. Liu, L.; Zhou, Y.; Zhou, G.; Ye, R.; Zhao, L.; Li, X.; Lin, Y. Identification of early senescence-associated genes in rice flag leaves. Plant Mol. Biol. 2008, 67, 37-55. [CrossRef] [PubMed] 
15. Liu, X.; Li, Z.; Jiang, Z.; Zhao, Y.; Peng, J.; Jin, J.; Guo, H.; Luo, J. LSD: A leaf senescence database. Nucleic Acids Res. 2010, 39, D1103-D1107. [CrossRef] [PubMed]

16. Tang, Y.; Li, M.; Chen, Y.; Wu, P.; Wu, G.; Jiang, H. Knockdown of OsPAO and OsRCCR1 cause different plant death phenotypes in rice. J. Plant Physiol. 2011, 168, 1952-1959. [CrossRef] [PubMed]

17. Sato, Y.; Morita, R.; Katsuma, S.; Nishimura, M.; Tanaka, A.; Kusaba, M. Two short-chain dehydrogenase/reductases, NON-YELLOW COLORING 1 and NYC1-LIKE, are required for chlorophyll b and light-harvesting complex II degradation during senescence in rice. Plant J. 2009, 57, 120-131. [CrossRef] [PubMed]

18. Kusaba, M.; Ito, H.; Morita, R.; Iida, S.; Sato, Y.; Fujimoto, M.; Kawasaki, S.; Tanaka, R.; Hirochika, H.; Nishimura, M. Rice NON-YELLOW COLORING1 is involved in light-harvesting complex II and grana degradation during leaf senescence. Plant Cell 2007, 19, 1362-1375. [CrossRef] [PubMed]

19. Xie, Q.; Liang, Y.; Zhang, J.; Zheng, H.; Dong, G.; Qian, Q.; Zuo, J. Involvement of a putative bipartite transit peptide in targeting rice pheophorbide a oxygenase into chloroplasts for chlorophyll degradation during leaf senescence. J. Genet. Genom. 2016, 43, 145-154. [CrossRef] [PubMed]

20. Wang, D.; Liu, H.; Zhai, G.; Wang, L.; Shao, J.; Tao, Y. OspTAC2 encodes a pentatricopeptide repeat protein and regulates rice chloroplast development. J. Genet. Genom. 2016, 43, 601-608. [CrossRef]

21. Uji, Y.; Akimitsu, K.; Gomi, K. Identification of OsMYC2-regulated senescence-associated genes in rice. Planta 2017, 245, 1241-1246. [CrossRef]

22. Lee, S.H.; Sakuraba, Y.; Lee, T.; Kim, K.W.; An, G.; Lee, H.Y.; Paek, N.C. Mutation of Oryza sativa CORONATINE INSENSITIVE $1 b$ (OsCOI1b) delays leaf senescence. J. Integr. Plant Biol. 2015, 57, 562-576. [CrossRef] [PubMed]

23. Fang, C.; Zhang, H.; Wan, J.; Wu, Y.; Li, K.; Jin, C.; Chen, W.; Wang, S.; Wang, W.; Zhang, H. Control of leaf senescence by an MeOH-Jasmonates cascade that is epigenetically regulated by OsSRT1 in rice. Mol. Plant 2016, 9, 1366-1378. [CrossRef] [PubMed]

24. Hou, K.; Wu, W.; Gan, S.S. SAUR36, a small auxin up RNA gene, is involved in the promotion of leaf senescence in Arabidopsis. Plant Physiol. 2013, 161, 1002-1009. [CrossRef] [PubMed]

25. Kant, S.; Bi, Y.M.; Zhu, T.; Rothstein, S.J. SAUR39, a small auxin-up RNA gene, acts as a negative regulator of auxin synthesis and transport in rice. Plant Physiol. 2009, 151, 691-701. [CrossRef] [PubMed]

26. Quirino, B.F.; Normanly, J.; Amasino, R.M. Diverse range of gene activity during Arabidopsis thaliana leaf senescence includes pathogen-independent induction of defense-related genes. Plant Mol. Biol. 1999, 40, 267-278. [CrossRef] [PubMed]

27. Van der Graaff, E.; Schwacke, R.; Schneider, A.; Desimone, M.; Flügge, U.I.; Kunze, R. Transcription analysis of Arabidopsis membrane transporters and hormone pathways during developmental and induced leaf senescence. Plant Physiol. 2006, 141, 776-792. [CrossRef] [PubMed]

28. Yang, X.; Gong, P.; Li, K.; Huang, F.; Cheng, F.; Pan, G. A single cytosine deletion in the OsPLS1 gene encoding vacuolar-type $\mathrm{H}+$-ATPase subunit A1 leads to premature leaf senescence and seed dormancy in rice. J. Exp. Bot. 2016, 67, 2761-2776. [CrossRef]

29. Su, M.; Huang, G.; Zhang, Q.; Wang, X.; Li, C.; Tao, Y.; Zhang, S.; Lai, J.; Yang, C.; Wang, Y. The LEA protein, $\mathrm{ABR}$, is regulated by $A B I 5$ and involved in dark-induced leaf senescence in Arabidopsis thaliana. Plant Sci. 2016, 247, 93-103. [CrossRef]

30. Woo, H.R.; Kim, H.J.; Nam, H.G.; Lim, P.O. Plant leaf senescence and death-regulation by multiple layers of control and implications for aging in general. J. Cell Sci. 2013, 126, 4823-4833. [CrossRef]

31. Besseau, S.; Li, J.; Palva, E.T. WRKY54 and WRKY70 co-operate as negative regulators of leaf senescence in Arabidopsis thaliana. J. Exp. Bot. 2012, 63, 2667-2679. [CrossRef] [PubMed]

32. Zhang, Q.; Xia, C.; Zhang, L.; Dong, C.; Liu, X.; Kong, X. Transcriptome Analysis of a Premature Leaf Senescence Mutant of Common Wheat (Triticum aestivum L.). Int. J. Mol. Sci. 2018, 19, 782. [CrossRef] [PubMed]

33. Han, M.; Kim, C.Y.; Lee, J.; Lee, S.K.; Jeon, J.S. OsWRKY42 represses OsMT1d and induces reactive oxygen species and leaf senescence in rice. Mol. Cells 2014, 37, 532. [CrossRef] [PubMed]

34. Hudson, D.; Guevara, D.; Yaish, M.W.; Hannam, C.; Long, N.; Clarke, J.D.; Bi, Y.M.; Rothstein, S.J. GNC and CGA1 modulate chlorophyll biosynthesis and glutamate synthase (GLU1/Fd-GOGAT) expression in Arabidopsis. PLoS ONE 2011, 6, e26765. [CrossRef] [PubMed] 
35. Zhang, C.; Hou, Y.; Hao, Q.; Chen, H.; Chen, L.; Yuan, S.; Shan, Z.; Zhang, X.; Yang, Z.; Qiu, D. Genome-wide survey of the soybean GATA transcription factor gene family and expression analysis under low nitrogen stress. PLOS ONE 2015, 10, e0125174. [CrossRef] [PubMed]

36. Lu, G.; Casaretto, J.A.; Ying, S.; Mahmood, K.; Liu, F.; Bi, Y.M.; Rothstein, S.J. Overexpression of OsGATA12 regulates chlorophyll content, delays plant senescence and improves rice yield under high density planting. Plant Mol. Biol. 2017, 94, 215-227. [CrossRef] [PubMed]

37. Uauy, C.; Distelfeld, A.; Fahima, T.; Blechl, A.; Dubcovsky, J. A NAC gene regulating senescence improves grain protein, zinc, and iron content in wheat. Science 2006, 314, 1298-1301. [CrossRef]

38. Sakuraba, Y.; Piao, W.; Lim, J.H.; Han, S.H.; Kim, Y.S.; An, G.; Paek, N.C. Rice ONAC106 inhibits leaf senescence and increases salt tolerance and tiller angle. Plant Cell Physiol. 2015, 56, 2325-2339. [CrossRef]

39. Zhou, Y.; Liu, L.; Huang, W.; Yuan, M.; Zhou, F.; Li, X.; Lin, Y. Overexpression of OsSWEET5 in rice causes growth retardation and precocious senescence. PLoS ONE 2014, 9, e94210. [CrossRef]

40. Krattinger, S.; Lagudah, E.; Spielmeyer, W.; Singh, R.; Huerta-Espino, J.; Mc Fadden, H.; Bossolini, E.; Selter, L.; Keller, B. An ABC transporter confers durable resistance to multiple fungal pathogens in wheat. In Proceedings of the 3rd 19th International Triticeae Mapping Initiative, COST Tritigen, Clermont-Ferrand, France, 31 August-4 September 2009.

41. Yang, S.S.; Tu, Z.J.; Cheung, F.; Xu, W.W.; Lamb, J.F.; Jung, H.J.G.; Vance, C.P.; Gronwald, J.W. Using RNA-Seq for gene identification, polymorphism detection and transcript profiling in two alfalfa genotypes with divergent cell wall composition in stems. BMC Genom. 2011, 12, 199. [CrossRef]

42. Ekblom, R.; Galindo, J. Applications of next generation sequencing in molecular ecology of non-model organisms. Heredity 2011, 107, 1. [CrossRef]

43. Mortazavi, A.; Williams, B.A.; McCue, K.; Schaeffer, L.; Wold, B. Mapping and quantifying mammalian transcriptomes by RNA-Seq. Nat. Methods 2008, 5, 621. [CrossRef] [PubMed]

44. Haas, B.J.; Zody, M.C. Advancing RNA-seq analysis. Nat. Biotechnol. 2010, 28, 421. [CrossRef] [PubMed]

45. Wang, J.; Islam, F.; Li, L.; Long, M.; Yang, C.; Jin, X.; Ali, B.; Mao, B.; Zhou, W. Complementary RNA-sequencing based transcriptomics and iTRAQ proteomics reveal the mechanism of the alleviation of quinclorac stress by salicylic acid in Oryza sativa ssp. japonica. Int. J. Mol. Sci. 2017, 18, 1975. [CrossRef]

46. Wang, Z.; Gerstein, M.; Snyder, M. RNA-Seq: A revolutionary tool for transcriptomics. Nat. Rev. Genet. 2009, 10, 57. [CrossRef] [PubMed]

47. Akhter, D.; Qin, R.; Nath, U.K.; Alamin, M.; Jin, X.; Shi, C. The Brown Midrib Leaf (bml) Mutation in Rice (Oryza sativa L.) Causes Premature Leaf Senescence and the Induction of Defense Responses. Genes 2018, 9 , 203. [CrossRef] [PubMed]

48. Ma, Z.; Tan, Y.; Cui, G.; Feng, Y.; Cui, Q.; Song, X. Transcriptome and gene expression analysis of DHA producer Aurantiochytrium under low temperature conditions. Sci. Rep. 2015, 5, 14446. [CrossRef] [PubMed]

49. Schön, M.; Töller, A.; Diezel, C.; Roth, C.; Westphal, L.; Wiermer, M.; Somssich, I.E. Analyses of wrky18 wrky40 plants reveal critical roles of $S A$ /EDS1 signaling and indole-glucosinolate biosynthesis for Golovinomyces orontii resistance and a loss-of resistance towards Pseudomonas syringae pv. tomato AvrRPS4. Mol. Plant-Microbe Interact. 2013, 26, 758-767. [CrossRef] [PubMed]

50. Yoshida, S. Molecular regulation of leaf senescence. Curr. Opin. Plant Biol. 2003, 6, 79-84. [CrossRef] [PubMed]

51. Kang, K.; Kim, Y.; Park, S.; Back, K. Evaluation of light-harvesting complex proteins as senescence-related protein markers in detached rice leaves. Photosynthetica 2009, 47, 638-640. [CrossRef]

52. Yamatani, H.; Sato, Y.; Masuda, Y.; Kato, Y.; Morita, R.; Fukunaga, K.; Nagamura, Y.; Nishimura, M.; Sakamoto, W.; Tanaka, A. NYC4, the rice ortholog of Arabidopsis THF1, is involved in the degradation of chlorophyll-protein complexes during leaf senescence. Plant J. 2013, 74, 652-662. [CrossRef] [PubMed]

53. Zoschke, R.; Watkins, K.P.; Miranda, R.G.; Barkan, A. The PPR-SMR protein PPR 53 enhances the stability and translation of specific chloroplast RNA s in maize. Plant J. 2016, 85, 594-606. [CrossRef] [PubMed]

54. Khan, M.; Rozhon, W.; Poppenberger, B. The role of hormones in the aging of plants-a mini-review. Gerontology 2014, 60, 49-55. [CrossRef] [PubMed]

55. Cock, P.J.; Fields, C.J.; Goto, N.; Heuer, M.L.; Rice, P.M. The Sanger FASTQ file format for sequences with quality scores, and the Solexa/Illumina FASTQ variants. Nucleic Acids Res. 2009, 38, 1767-1771. [CrossRef] [PubMed] 
56. Langmead, B.; Trapnell, C.; Pop, M.; Salzberg, S.L. Ultrafast and memory-efficient alignment of short DNA sequences to the human genome. Genom. Biol. 2009, 10, R25. [CrossRef] [PubMed]

57. Kim, D.; Langmead, B.; Salzberg, S.L. HISAT: A fast spliced aligner with low memory requirements. Nat. Methods 2015, 12, 357. [CrossRef] [PubMed]

58. Li, B.; Dewey, C.N. RSEM: Accurate transcript quantification from RNA-Seq data with or without a reference genome. BMC Bioinform. 2011, 12, 323. [CrossRef]

59. Zeng, D.D.; Qin, R.; Li, M.; Alamin, M.; Jin, X.L.; Liu, Y.; Shi, C.H. The ferredoxin-dependent glutamate synthase (OsFd-GOGAT) participates in leaf senescence and the nitrogen remobilization in rice. Mol. Genet. Genom. 2017, 292, 385-395. [CrossRef]

60. Livak, K.J.; Schmittgen, T.D. Analysis of relative gene expression data using real-time quantitative PCR and the $2^{-\Delta \Delta \mathrm{CT}}$ method. Methods 2001, 25, 402-408. [CrossRef]

(C) 2019 by the authors. Licensee MDPI, Basel, Switzerland. This article is an open access article distributed under the terms and conditions of the Creative Commons Attribution (CC BY) license (http://creativecommons.org/licenses/by/4.0/). 